\title{
Particle Orientation Distribution in Alumina Compact Body Prepared by the Slip Casting Method
}

\author{
Satoshi TANAKA, Atsushi MAKIYA, Shinya WATANABE, Zenji KATO, \\ Nozomu UCHIDA and Keizo UEMATSU \\ Department of Chemistry, Nagaoka University of Technology, 1603-1, Kamitomioka-cho, Nagaoka-shi 940-2188
}

\author{
スリップキャスト法で作製されたアルミナ成形体における粒子配向構造 \\ 田中 諭·牧谷 敦·渡辺信也 · 加藤善二 · 内田 希·植松敬三 \\ 長岡技術科学大学工学部化学系, 940-2188 長岡市上富岡町 1603-1
}

\begin{abstract}
The packing structure of particles is studied for alumina compact made by slip casting, with an emphasis placed on the local orientation of particles. The orientation is visualized and analyzed quantitatively using an optical method, which is based on the measurement of optical anisotropy using a polarized microscope. In the measurement, the compact is soaked in an immersion liquid to make it transparent, and is observed by a crossed polarized optical microscope to determine the retardation of the compact with a compensator. The degree of particle orientation is defined as the ratio of birefringence of the compact and that of alumina single crystal. The degree of particle orientation is found to be 3-9\%. The structure of the compact is found to have a close relevance to the draining direction of slurry in casting.

[Received January 6, 2004; Accepted March 23, 2004]
\end{abstract}

Key-words : Particle orientation, Alumina, Slip casting, Green body, Polarized microscope

\section{Introduction}

In designing and controlling the processing of ceramics, it is desirable to characterize the packing structure of particles in green compacts, since it governs shrinkage and deformation during sintering and also the characteristics of sintered body. ${ }^{1)}$ A recent paper showed a marked effect of particle orientation on processing. ${ }^{2)-9)}$ A clear relevance was noted between the particle orientation and the deformation during sintering for a die-pressed alumina compact made with an industrial grade alumina powder, for which the powder has slightly elongated shape. ${ }^{5)}$ Even a very weak particle orientation, detectable only by the novel characterization tool, causes significant deformation of green compacts in sintering. Much more strong particle orientation is expected in a compact made by slip casting. ${ }^{10), 11)}$ It should be interesting to analyze the packing structure of the compact made by this forming method, since there are still various unsolved problems in this forming method.

The purpose of this study is to visualize and analyze the packing structure of particles in alumina compact made by slip casting with the liquid immersion method mixed using a traditional method. Crystal system of alumina is hexagonal and has optical anisotropy; alumina crystal has two refractive indices, one is ordinary light and the other is extra-ordinary light. The green compact has also optical anisotropy if orientation structure exists in it. The particle orientation should be observed using the polarized light microscope. The degree of orientation will be determined quantitatively through the measurement of birefringence of the compact.

\section{Experimental procedure}

2.1 Preparation of slip casting compact

Commercial $\alpha$-alumina powder (AL160SG1, Showa Denko K. K., median size $0.6 \mu \mathrm{m}$ ) was used as a raw material. Shape of particle is elongated and not spherical. Aspect ratio of the particle was about 1.6.5) The shortest axis of particle is $c$-axis, since $c$-face of alumina is easy to be developed as a major face of particles. ${ }^{12)}$ The powder was dispersed in distilled water with a dispersant 0.5 mass\% (Seruna D305, Chukyo Yushi, Co., Ltd.) and ball milled for $24 \mathrm{~h}$ to make a slurry of the solid loading $50 \mathrm{vol} \%$. The slurry was poured into a gypsum mold (Fig. 1). After removed from the mold, the cast green compact $(60 \mathrm{~mm} \times 60 \mathrm{~mm} \times 7 \mathrm{~mm})$ was dried for a week at the room temperature. The dried compacts were calcined at $1000^{\circ} \mathrm{C}$ to remove the dispersant.

2.2 Visualization of the orientation structure of particles and quantitatively evaluation of orientation degree in the compact

A crossed polarized light microscope with a white light and a sensitive color plate $(n=530 \mathrm{~nm})$ was used to survey the macrostructure of the compact. A thin specimen $(0.2 \mathrm{~mm}$ thick) was prepared from the compact by ground with a sand

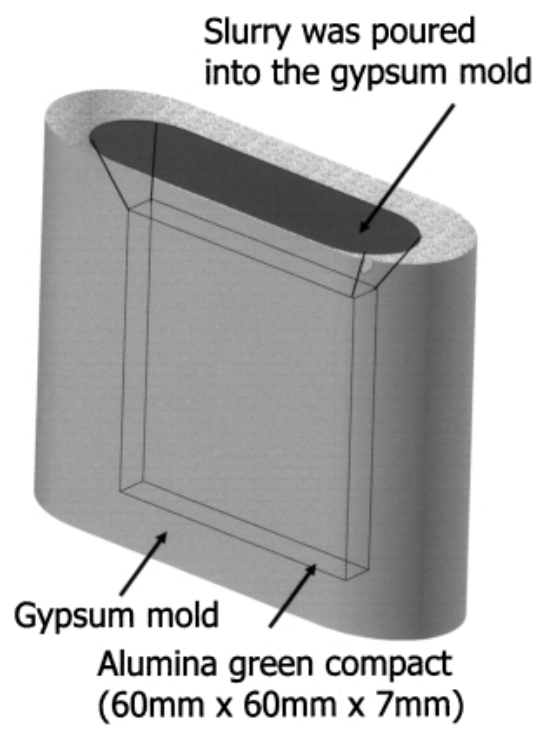

Fig. 1. Schematic illustration of a gypsum mold. 


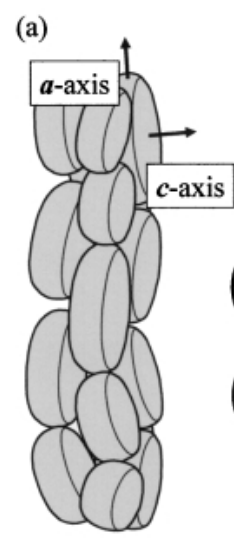

green compact (b) $\mathrm{R}_{\text {compact }}=\mathrm{d} \cdot \rho \cdot \Delta \mathrm{n}_{\text {compact }}$

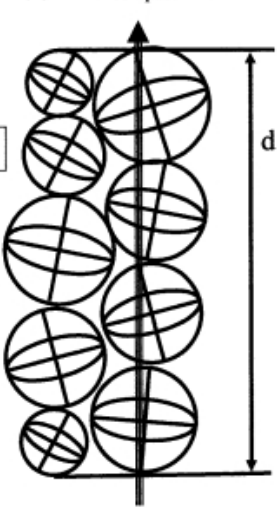

Retardation in green compact (c)

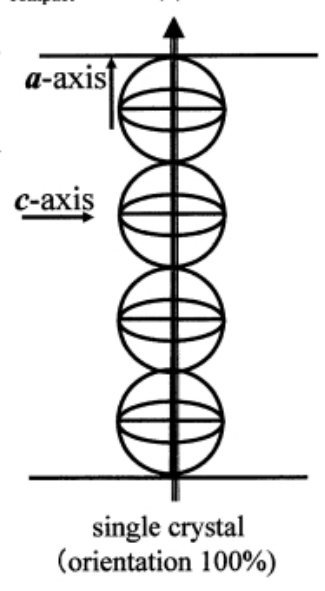

Fig. 2. Concept of evaluation method based on the optical anisotropy for alumina (a) a model for particle orientation in the green compact, (b) an illustration of the birefringence of each particle in the green compact, (c) an illustration of the birefringence of single crystal.

paper. Diiodomethane (Refractive Index: 1.74 ) was added to make the thin specimen transparent.

The degree of particle orientation in the green compact was measured using an optical method. Figure 2 shows the concept of the measurement method of the degree of particle orientation based on the optical anisotropy for alumina. The longest axis ( $a$-axis) in particles with elongated shape is assumed to be orientated parallel to the gypsum face (Fig. $2(\mathrm{a})) .{ }^{10)}$ In a filtration method, the shortest axis of particles is known to be orientated perpendicular to the filter surface. The degree of particle orientation $f$ for the compact along the direction of the longest axis ( $a$-axis) of hexagonal alumina is defined as the ratio of apparent birefringence of the compact $\Delta n_{\text {compact }}$ to that of alumina single crystal $\Delta n_{\text {single }}$ crystal, as follows,

$$
f=\frac{\Delta n_{\text {compact }}}{\Delta n_{\text {single crystal }}}=\frac{\Delta n_{\text {compact }}}{0.0075}
$$

In this equation, the birefringence of alumina viewed from the direction parallel to $a$-axis (perpendicular to $c$-axis) is $0.0075 .{ }^{13)}$ The value $f$ ranges from zero to one. The former corresponds to no orientation and the latter the complete orientation.

The birefringence of alumina compact $\Delta n_{\text {compact }}$ was calculated from the retardation $R_{\text {compact }}$ for a compact, which was measured with the Berek compensator. As shown in Fig. 2 (b), we assume the measured retardation $R_{\text {compact }}$ for a compact was given as follows, ${ }^{14}$

$$
R_{\text {compact }}=d \cdot \rho \cdot \Delta n_{\text {compact }}
$$

where, $\Delta n_{\text {compact }}$ is the birefringence of the compact. $d$ is the thickness of the observation sample. The relative density $\rho$ appears in the equation, since pores between particles make no contribution to the retardation. The product $d \cdot \rho$ corresponds to the total length of the solid, through which the polarized light travels and interacts with the solid. The birefringence of alumina compact $\Delta n_{\text {compact }}$ be calculated from dividing the retardation $R_{\text {compact }}$ by the product $d \cdot \rho$. The relative density $\rho$ was measured with the Hg-porosimetor (Model 9310, Shimadzu).

\section{Result and discussion}

Figure 3 shows the crossed polarized light micrograph for the specimen cut form a green compact near the bottom as shown schematically in the Fig. 3. Regions of different colors are noted in the micrograph, suggesting the local change of the particle orientation. The color of each region changed repeatedly from blue to pink and then to yellow with its rotation for every $45^{\circ}$ as shown in Fig. 3. Clearly the particle orientation is established by the water flow in the slurry during casting, and thus is governed by the geometry of the gypsum mold. A narrow pass of width approximately $10 \mu \mathrm{m}$ is observed at the center of the compact (arrow in Fig. 3). The observed color change with rotation shows that particles in this region are orientated to a direction almost perpendicular to particles in both sides.

Figure 4 shows detailed micrographs for a few regions in Fig. 3. The regions selected are the center, edge and corner of the compact (Figs. 4(a)-(c)). The direction of particle orientated is summarized in Fig. 5. Large particles with size over about $5 \mu \mathrm{m}$ (arrows in Fig. 4(b)) are noted at various places. Their longest axes are aligned parallel to the wall of the mold at all places near the wall, except the corner. With the rotation of the specimen under microscope, these large particles and the surrounding matrix showed the same color change. This color change suggests that small matrix particles and the large particle are orientated to the same direction, although the former particles are too small to identify their orientation individually. This observation is consistent with the past result. ${ }^{12)}$ The particle with elongated shape is known to be orientated with their longest axes parallel to the surface of the gypsum mold. In the corner region, two regions, blue and yellow regions, are identified (Fig. 4 (c)). These colors exhibit that the particles in two regions are orientated perpendicular to each other, since the blue and yellow colors are contributed to each vibrate direction of the polarized light through the particles. Blue and yellow observed at the same time in the polarized micrograph show that their vibrate directions are perpendicular to each other. The result is supported by the color changing that blue region changed to the yellow with rotation for $90^{\circ}$ in the specimen, whereas yellow region changed to blue (Fig. 3). Clearly, the direction of gypsum surface nearest to the growing powder cake governs the direction of particles orientation. Particles are also orientated in the central line (Fig. 4(b)). The particles located in this region receive forces from the particles in both sides, and align perpendicular to the particles on both sides. The detailed mechanism for the formation of this structure will be clarified in the continuous study.

Figure 6 shows a photograph taken from the direction perpendicular to that in Fig. 3. The observed surface is directly parallel to the surface of the gypsum mold. The color remains pink for all angles of rotation in its micrograph. It would appear that $c$-axes of particles are orientated perpendicular to gypsum mold, and that the $a$-axes of particles are randomly orientated in parallel to the mold surface when observed from this direction, making the structure optically isotropic.

Figure 7 shows the close-up view of the macrostructure of the compact, the degree of particle orientation and the direction of orientation for the same region shown in Fig. 3. The symmetric values were noted in the degree of particle orientation with respect to the central line. The maximum value $9 \%$ was found in the degree of orientation, suggesting that the particles are orientated moderately in the slip casting. Our experiences show that this degree of orientation is much too small to be detected by the X-ray diffraction analysis. It is interesting to note that the degree of orientation is rather low near the edge and increased towards the center of the compact. 


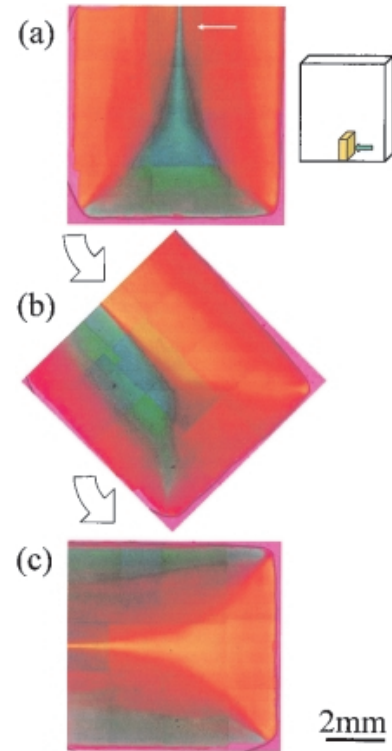

Fig. 3

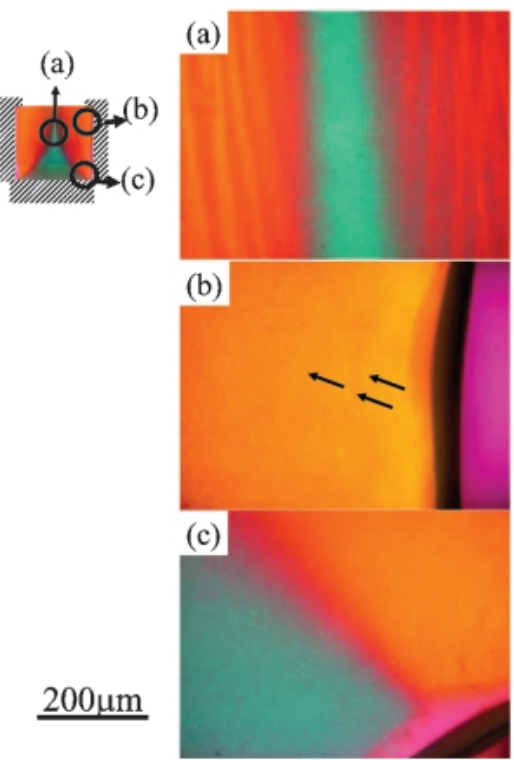

Fig. 4

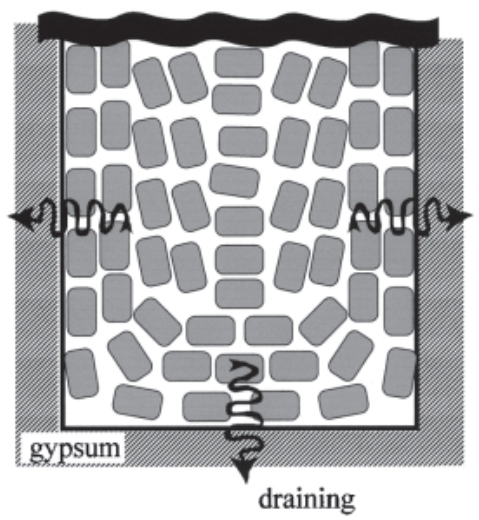

Fig. 5

Fig. 3. Crossed polarized light micrograph for the specimen cut form a green compact near the bottom.

Fig. 4. Detailed micrographs for a few regions in Fig. 3, the regions selected are edge (a), center (b) and corner (c) of the compact.

Fig. 5. Direction of particle orientation.

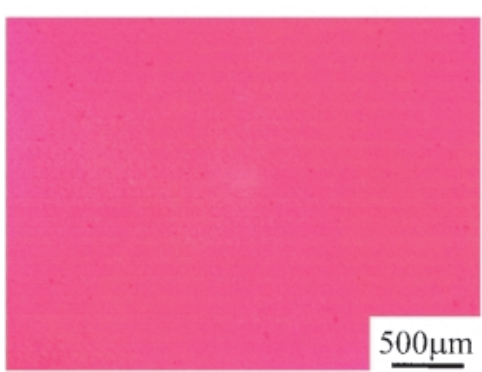

Fig. 6

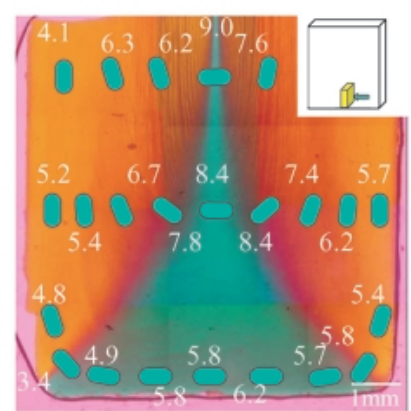

Fig. 7

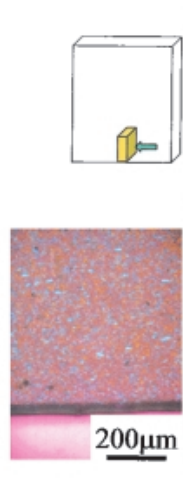

$\mu \mathrm{m}$

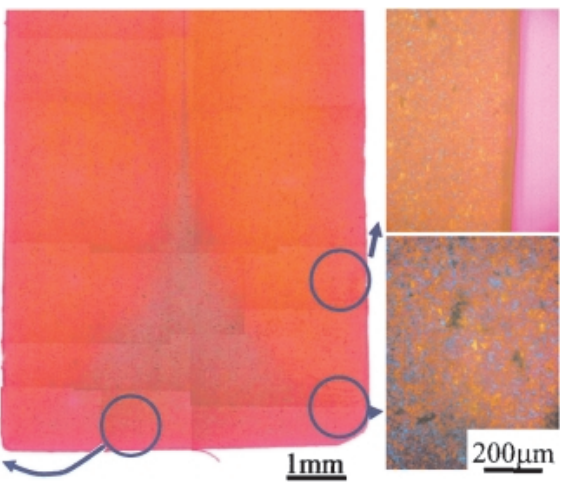

Fig. 8

Fig. 6. Photograph taken from the direction perpendicular to that in Fig. 3.

Fig. 7. Close-up view of the macrostructure of the compact, the degree of particle-orientation and the direction of orientation for the same region shown in Fig. 3.

Fig. 8. Crossed polarized light micrograph of the compact sintered at $1550^{\circ} \mathrm{C}$.

This result can be explained by the change of flow rate of water in the molding process. At the beginning of the molding process, the absorption of water into the mold and thus the flow of water are very rapid, and the particles have not enough time to settle in the most stable position at the interface of slurry and the growing cake deposited already on the mold. Particles orientation is weak in this stage. After a thick cake have deposited on the mold, the water flows slowly and the particles have enough time to rearrange to be settled in the most stable position, and thus be highly orientated at the interface. The orientation should be high in the region developed in the later stage of casting.

Figure 8 shows the crossed polarized light micrograph of the compact sintered at $1550^{\circ} \mathrm{C}$. A thinned specimen $(0.1 \mathrm{~mm}$ thick) was observed with a transmitted light. The specimen was prepared from the sintered body by ground with a machining apparatus. The specimen was polished to miller surface to suppressing reflection. A comparison with Fig. 7 shows that the structure of particle orientation is essentially the same before and after sintering. Clearly, the structure of particle orientation is preserved after sintering. Grain growth was noted in the sintering. The influences of particle orientation on sintering, anisotropic shrinkage, and properties, etc., are interesting subject to be discussed further in subsequent papers.

\section{Conclusions}

The optical method was applied to analyze the packing structure in alumina compact made by slip casting in this study. In this method, the specimen was made transparent with an immersion liquid. The orientation was evaluated quantitatively with a novel optical method, which was based on the measurement of optical anisotropy with a polarized microscope. The degree of particle orientation was defined as 
the ratio of birefringence of the compact and that of alumina single crystal perpendicular to $c$-axis. The structure of the compact was found to have a close relevance to the draining direction of slurry in casting. The degree of particle orientation was found to be $3-9 \%$. The value obtained will be conveniently used to compare the local change of orientation within the compact.

Acknowledgement This research was partly supported by Grant-in-Aid for Scientific Research (No. 11305045) from the Japan Ministry of Education, Culture, Sports, Science and Technology, and Nippon Sheet Glass Foundation for Materials Science and Engineering. We are grateful to Mr.Yoshihiro Todaka and Mr. Hisanori Yokoyama at Gifu Prefectural Ceramic Research Institute for their courtesy and assistance in preparing compact by slip casting.

\section{References}

1) Lang, F. F., J. Am. Ceram. Soc., Vol. 72, pp. 3-15 (1989).

2) Uematsu, K., Tanaka, H., Zhang, Y. and Uchida, N., J. Ceram. Soc. Japan, Vol. 101, pp. 1400-1403 (1993).

3) Uematsu, K., Ohsaka, S., Shinohara, N. and Okumiya, M., $J$. Am. Ceram. Soc., Vol. 80, pp. 1313-1315 (1997).
4) Shui, A., Zhang, Y., Uchida, N. and Uematsu, K., J. Ceram. Soc. Japan, Vol. 106, pp. 873-876 (1998).

5) Shui, A., Kato, Z., Tanaka, S., Uchida, N. and Uematsu, K., Am. Ceram. Soc. Bull., Vol. 80, pp. 29-32 (2001).

6) Shui, A., Kato, Z., Tanaka, S., Uchida, N. and Uematsu, K., J. Eur. Ceram. Soc., Vol. 22, pp. 311-316 (2002).

7) Shui, A., Uchida, N. and Uematsu, K., Powder Technology, Vol. 127, pp. 9-18 (2002).

8) Shui, A., Makiya, A., Tanaka, S., Uchida, N. and Uematsu, K., J. Ceram. Soc. Japan, Vol. 110, pp. 264-269 (2002).

9) Makondeya, P. R. and Cannon, R. W., J. Am. Ceram. Soc., Vol. 82, pp. 2619-2625 (1999).

10) Takao, Y., Hotta, T., Naito, M., Shinohara, N., Okumiya, M. and Uematsu,K., J. Eur. Ceram. Soc., Vol. 22, pp. 397-401 (2002).

11) Hotta, Y., Abe, H., Naito, M., Kamiya, H. and Uematsu, K., Ceramic Transaction, Vol. 133, pp. 159-164 (2002).

12) Handwerker, C. A., Morris, P. A. and Coble, R. A., J. Am. Ceram. Soc., Vol. 72, pp. 130-136 (1989).

13) Shelly, D., "Optical mineralogy 2nd ed.," Elsevier (1985) pp. 278-278.

14) Makiya, A., Tanaka, S., Uchida, N. and Uematsu, K., Am. Ceram. Soc. Bull., to be submitted. 